transparency of disclosure of potential conflicts of interest by acknowledging these relationships in publications and presentations.

\section{P17.39 MONITORING OF THE SCALE-UP OF ANTIRETROVIRAL THERAPY PROGRAMMES IN SRI LANKA: EXPERIENCE FROM A RESOUECE LIMITTED AND LOW PREVALENCE SETTING}

Aka Manathunge*. National STD AIDS Control Program, Ministry of Health, Sri Lanka

10.1136/sextrans-2015-052270.617

Introduction Currently Sri Lanka uses a paper based monitoring and evaluation (M\&E) system for the antiretroviral therapy (ART) program which was adapted and modified from the system introduced by the World Health Organization (WHO). These modifications have been adapted keeping in mind that significant disparities exist in different regions in the same country. This paper summarises the findings of the M\&E system of the ART program in Sri Lanka where HIV epidemic is considered as low prevalent.

Methods Information sources of the current ART M\&E system was reviewed. Data generated by the M\&E system is analysed to evaluate the ART program of the country.

Results A cumulative total of 812 people living with HIV (PLHIV) were started on ART since the beginning of the ART program in 2004. Currently there are 647 PLHIV on ART. Of the patients who initiated ART, 75\% of PLHIV are on first line ARVs and 5\% are switched to second line ARV. The balance $20 \%$ comprised of loss-to-follow ups and deaths. The cohorts analysis of PLHIV on ART showed that after 12 months of ART initiation, 91\% are Alive and on ART while $86 \%$ and $76 \%$ are Alive and on ART after 24 months and 60 months respectively. Conclusion A paper based M\&E system can give very useful M\&E information in a resource poor and low HIV prevalence setting. However, a development of a suitable online M\&E system would greatly improve the data collection process as ART provision is a lifelong monitoring process.

Disclosure of interest statement No grants were received in the development of this study.

\section{P17.40 USING EFFECTIVE SUPPORT GROUP MEETINGS TO IMPROVE AND SUSTAIN SUPPORT GROUP MEMBERSHIP: THE EXPERIENCES AND OUTCOMES OF SUPPORT GROUPS IN NORTH-CENTRAL NIGERIA}

0 Omotoso*. Management Sciences for Health

\subsection{6/sextrans-2015-052270.618}

Introduction Sustaining interest and membership of Support Groups (SG) was a huge challenge after the withdrawal of material incentives. SGs were initially provided with material supports as incentives however this was not sustainable. SG membership and meeting attendance dropped drastically to $<10 \%$ in some cases. This challenge led to an innovation: using effective and activity oriented SG meetings to improve SG membership and attendance in north-central Nigeria.

Methods In 2012, the PEPFAR-USAID funded Pro-ACT project implemented by MSH conducted a data audit to know the number, frequency of PLWHAs who attend monthly support group meetings (SGM), and activities. Six members from three SGs were trained on conducting effective SGM and facilitating viable income generating activities. The SGM facilitators conducted meetings with specific agenda which incorporated health education, adherence; information sharing, psychosocial support and IGA.

Results A review of the intervention after six months showed an increase in SG membership and attendance from $<10 \%$ to $70 \%$ after the intervention, the trained SG facilitators used a well-organized agenda and completed the SGM within 90 to 120 minutes making SGM more effective, efficient and productive. They facilitators included follow-up visit to members' homes to ensure drug adherence and participation in SG activities. The PLHWAs now have a sense of ownership and belonging of the SG and facilitate their SGM with minimal support. They have also formed a Savings and Loan Association (SLA) in the process of transforming the support group to a $\mathrm{CBO}$ and have succeeded in accessing grant worth \#4.5 Million $(\$ 28,125)$ from FADAMA III Grant.

Conclusion PLHWAs participate more during SGM when given the opportunity to own their SG. Facilitating SGs affords them the opportunities to improve adherence, strengthen group formation and also access local fund for development. Organizations implementing HIV programs need to identify the opportunities of SGs been self-sufficient.

Disclosure of interest statement This work was carried out in Nigeria by Management Sciences for Health on the project Prevention Organizational Strengthening, AIDS, Care and Support (Pro-ACT).

\section{P17.41 HIV AND AIDS PROGRAMMING FOR PEOPLE WITH DISABILITIES ON ANTIRETROVIRAL THERAPY (ART) IN ZAMBIA}

Denis Chibuye* ${ }^{*}$ Mwewa Nkhoma Liswaniso. TALC

10.1136/sextrans-2015-052270.619

Background People with disabilities are less likely to access antiretroviral therapy (ART) services in health centre facilities and communities, which are often not sensitive to their special needs. This study explored stigma and discrimination, perceptions and local understandings of ART and HIV testing.

Methods Purposive sampling was applied in selection of participants from 3 districts namely, Mazabuka, Kapiri Mponshi and Lusaka. The selection took into consideration the need to reflect geographical, religious, social diversities so that lessons drawn there from are more likely to be applied across Zambia and the region. It was carried out in 15 health facilities, 15 support groups and 4 referral government hospitals. 120 respondents with different degrees of disabilities and 34 able bodied medical personnel were interviewed for this data collection.

Results Only $60 \%$ of people with disabilities interviewed in the study reported that they were not satisfied with ART and HIV testing services they received. The assessment found the gap in access to ART services for people with disabilities to be due to stigma, long distance to health facilities and lack of disability guidelines. 50\% of the respondents said that ART services are not user friendly for people with disabilities, this was equally supported by $60 \%$ of the health care providers interviewed. 